\title{
DOS CONTRATOS ADMINISTRATIVOS
}

\author{
José Saldamha da Gama e SH.va
}

SUMÁRIO : I - Conceituação dos contratos administrativos dentro do Direito Público ou do Direito Privado. II - $O$ determinismo histórico de o Estado ter do contratar com os particulares. $A$ siturçäo presente o a vigência dos principios hedonísticos. A pletora adminiatrativa e a racionalizaçäo das formas contratuais. III - A vontade estatal e a vontade individual. Prevalência da órbita ostatal - as conventionis juris gentium. IV - A evoluçāo do conceito do contrato. Diferença entre o nezum - vinculo essencial - o o contrato - vínculo formal. $V-O$ formalismo do pacto administrativo. $A$ conventio administrativa $e$ as caracteristicas dos contratos do marché-de-gré-à-gré. $A$ policitatio como instrumento de accordage. $A$ tendência atual para a uniformidade e a impessoalidade dos contratos. VI - A impossibilidade de uma diferenciação completa entro o Direito Público e o Direito Privado. A reciprocidade de condicionamento entre o Direito Público e o Direito Privado. VII - Palência das classificações atuais. Predominância do interêsse coletivo. Classificação teleológica para os contratos administrativos.

I - Dificilmente poderiamos encontrar assunto mais versado que os contratos administrativos. Problema de todos os dias, vem tentando a argúcia dos mais abalizados tratadistas do Direito Público - de Dugurt a Garno Fraga; de Laband a Adolf Giaquinto.

Entre nós, a matéria tem apaixonado os estudiosos. Além de merecer - carinho especial dos nossos mais conhecidos, tratadistas do Direito Administrativo - de Uruguai a Temistocles Cavalcanti ou Matos de Vasconcasos - tem servido nāo raro de assunto para algumas teses, ora de um professor renomado, como a do Prof. MÁrfo Mazagño ${ }^{1}$, onde o assunto vem profusamente tratado; ora de um estudante desconhecido, como a do então universitário MaNuEz DE OLIVEIra Franco SOBRINHo 2, onde a exaltação do adoleccente supre a bisonhice do jurista. 1933.

1 Mario Mazagĩo, Natureza Juridica de Concamio de Serviço Público, Sāo Paulo,

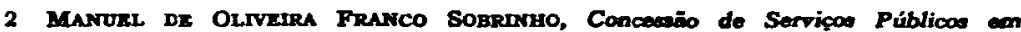
Direito Administrativo (tese aprenenteda 20 1. Congremo Juridico Univernitírio do Branil, reunido cidade do Salvador), Curitiba, 1936. 
Se indagarmos da razão de todo êsse empenho em discutir o problems, a resposta ocorrerá pronta: dificilmente poderemos encontrar assunto mais controvertido que os contratos administrativos.

Questão mais velha que os próprios contratos de Direito Privado - já que a locatio conductio operis (contrato entre a Administraçäo e o particular, segundo o qual êste se obrigava a realizar determinada obra pública) surgiu em Roma antes de serem conhecidas as fórmulas de contrato privado ${ }^{3}$-. os contratos administrativos até hoje vêm sendo debatidos de mil e uma formas, por mil e um autores, os quais divergem sistemàticamente, a não ser quando seguem o mesmo mestre.

Nota-se mesmo uma tradiçāo - que felizmente não é só brasileira -sem dúvida abalizada naqueles três exuberantes volumes que Jìze encheu para salientar as dificuldedes dos chamados contratós administrativos, segundo a qual se é logo obrigado a decidir: a favor de JÈzk, ou contra JÈze?

E' que Gaston Jìze, tentando concilíar os elementos de formaçäo eo elementos de execução dos contratos administrativos, parece ter definitivamente controvertido a matéria. Enumerando seus quatro "elementos essenciais" ì formação dos contratos (I - acôrdo de vontades; II - acôrdo bilateral da vontades - frisou logo depois; III - criação de uma situação jurídica; IV que a situação juridica surgida seja individual e não (eral) ${ }^{4}$, e glosando estas quatro inflexíveis máximas, explica que nem fodo acôrdo de rontades ́́ contrato, levando-nos até a duvidar da existência dos contratos administrativos, tais as limitações que lhes impöe, confiante em que a idéia de justiça pode aqui ter outras conseqüências muito diversas daquela que rege os contratos particulares.

Dêsse modo, se no primeiro e terceiro volumes de sua obra citada estuda a formação e execução dos contratos administrativos, dentro do Direito Público francês, no segundo volume chega a afirmar que aquelas relaçōes contratuais resultam não das fórmulas que as regem, mas das idéias que estas porventura exprimam ${ }^{5}$, o que sem dúvida impugna tècnicamente a validade formal de qualquer contrato, levando-o à situação de mero pacto, sujeito mesmo à teoria da imprevisáo, como se estuda no seu terceiro volume.

Entre nós, a maioria vai aceitando o célebre autor francês, embora procuremos identificar seus requisitos com os dos contratos de Direito Privado. Veja-se, por exemplo José Matos dE VAsconczios, que coteja os fundamentos basilares entre uns e outros - acôrdo de vontades; objeto lícito a forma prescrita ou não defesa em lei; capacidade das partes - para. terminar afirmando que seus pontos de divergência constitnem apenas "elementos esperíficos, próprios, tendo em vista a finalidade ditada pelo interêsse público em jogo, quanto à estipulação, aprovação e execução dos mesmos contratos" ".

Assim, tambéni, entre outros, Gutmaräes Menegal. e Trto Prates da FONSECA, que terminam por, dando ao interêsse público "precedência" sôbro interêsse privado, reconhecer a completa autonomia dos contratos adminis. trativos, "que são de direito público, distintos dos de direito civil" "

\footnotetext{
3 Veja-se Otro Marzr, Histoire du Droit Romain, Paris, 1907, livto I, seçāo II,

4 Gaston Jìze, Les Contrats Administratifs de l'Etat, dos Départements, des Com. munes et des établissaments Publics, Paris, 1927, vol. II, pág. 5.

5 JÈzE, op. cit., II, pág. 205.

6 Jose Matos de Vasconcelos, Direito Administrativo, Rio, 1937, vol. II, pág. 223

7 J. Gumaries Menegale, Direito Administrativo o Ciência da Administragáo. Rio, 1938-1939, tomo II, págs. 175 e segs.
} 
Na literatura universal as controvérsias são muito mais acirradas, sustentando-se por luminares como Kelsen, LABAND ou JeLINECK; CARNELUTtr, RacGi ou SANTI ROMano.

Já vimos, em primeiro lugar, aquêles que invalidam a existência técnica dos contratos administrativos, coma Jìze o Orro MAYrR, para os quais, afinal, o atos qualificados como contratos administrativos não passam de simples atos administrativos.

Em segundo lugar, podemos citar aquêles que, ao contrário, emprestam aos contratos administrativos caracteres de veros contratos de Direito Público, como Crno VITTA, Forti ou o japonês Yorodzu ODA, que lembra, por exemplo, - perfeito acôrdo de vontades entre órgãos da Administração Pública ${ }^{8}$.

Em terceiro lugar, podemos citar autores como MKrio Gallo, premiado em 1934 pelo Istituto Nazionale di Previdenza e Mutualità - expoente da moderna corrente italiana - que, fazendo distinção entre as noçöes de unilateralidade e bilateralidade no Direito Público e no Direito Privado, admite apenas haver no caso não uma contratualidade substancial, mas simplesmente formal 9 .

Em quarto lugar, temos os tratadistas que dão aos contratos administrativos as mesmas características dos contratos privedos, equiparando-os, filiados todos à tese universalista de LÉon Dugurr 10, para quem os caracteres contratuais são sempre os mesmos, em qualquer espécie de contrato.

Como representante extremo desta última corrente, podemos salientar RAFAEI BiELSA, cuja tese chega a classificar taxativamente certos contratoa administrativos como verdadeiros contratos de direito privado, como se vê: "se não se trata de satisfazer um serviço dessa îndole (prestação de utilidade pública) a Administração Pública se colocará no mesmo plano que os particulares; então, o contrato será de direito privado" 11.

Como se percebe, rebuscando alguns autores, chegamos a discernir as mais contraditórias convicçōes, desde aquelas que negam a existência dos contratos administrativos, àquelas que os encaram como categoria à parte, e até mesmo àquelas que os confundem com os contratos de direito privado.

Dá porque tal disparidade de opinióes chegou a desencorajar um dos grandes especialistas na matéria - JEAN Rouvnk̀RE - que confessou, vencido: "a conclusão à qual se é obrigado a chegar é a seguinte: todos os esforços tentados para destacar os caracteres distintivos dos contratos administrativos, para inseri-los em uma só fórmula, foram baldados. Este fracasso era inevitável. Em verdade, os contratos administrativos jogam, em essência, com todos os princípios e regras do Direito Administrativo. Estes principios e estas regras são muito numerosos. Sua importância cresce com o Direito Administrativo. E não é possível salientar em uma única fórmula os caracteres de todos os contratos concluídos dentro dêste vasto domínio" 12 .

Ciosos desta verdade, buscaremos aqui ventilar o problema, tentando um paradoro: alargar-lhe os têrmos para simplificar-lhe a solução.

II - O determinismo de o Estado ter que pactuar com os particulares vem de longe. Já na era antecristã os gregos elegiam anualmente seus dez tesoureiros - hellenotamiai, a cuja presença os responsáveis por qualquer função administrativa vinham prestar contas; aquêles, por sua vez, prestavam

8 Yorodzu ODA, Principes du Droit Administratil du Japon, Paris, 1928, pág. 85.

9 MArio Gallo, I rapporti contrattuali nel Diritto Amministrativo, Padua, 1936, páce. 119.

10 Lton Dugurr, Le Droit Constitutionel, Paris, 1923, vol. II, pág. 41.

11 Rafael Brelsa, Derecho Administrativo, Bueno Aires, 1937, tomo I, pág. 255.

12 JEAN RouviErr, Les Contrats Administratifs, leurs caractòres distinctifs d'aprde la jurrisprudence, Paris, 1930, pág. 44. 
contas ao povo. Como se vê, métods democrático die tomada de contas at pasteriori, com perfeito sistema de contrôle administrativo interno e externo...

Mas ouțas formas de relaçōes entre o Estado e o particular se forama desenvolvendo, como a concorrência pública para a venda das presas đo guerra; assim, já no direito romano vamos encontrar a sub-asta, processo de licitaçãe? para aquêle fim.

Este processo de concorrência - sintoma claro de acôrdo de vontadę - se vai tornando usual: o código de Justiniano, por exemplo, consigna o regime da venda de bens fiscais em hasta páblica, e mais tarde poderemos encontrar verdadeiros contratos administrativos - como o já mencionado de locatio conductio operis - que se efetuavam mediante concortência pública, conforme nos ensina MAYR ${ }^{13}$.

Lembre-se também que Justiniano autorizava a expropriação de imóveis pertencentes aos eclesiásticos - não obstante seus privilégios - em razão de um instituto de utilitatem reipublicae respiciens, mediante uma indenizaçāo prévia, a Indemnitate servata 14 .

Passado o feudalismo, os estados neo-surgentes imitam a velha licão romana: Henriģue IV, na França do século XVI, baixa ordenanças sôbre as obras públicas. E se e século XVII viu em Colbert um ardente defensor do regime de concortência, o século $\mathrm{XIX}$ veria no Regulamento Geral de Contabilidade a consignação daqueles antigas normas.

O exemplo francês corre munço, passa à Inglaterra, à Itálía, etc., alargando o sistema de licitações e adjudicaçōes privadas que caracterizam airıda hoje um vero regime de marché-de-gré-ì-gré.

No momento presente, o tema se esbordou agudamente, apresenterido aspectos distintos, não só juridicos e contábeis, mas também adrainistrativos e financeiros, econômicos e sociais.

O crescimento cotidiano das funçöes do Estado e os seus variegados problemas de subsistência tornam anacrônicos e sediços os cânones do passado: tendendo a uma base cada vez mais de índole econômica, a gestão financeirs do Estado vai descambando para o princípio hedonístico, no seu mais amplo sigrificado socialista.

Assim, multiplicam-se os contratos da Administração, tendo por objeto: ora a provisão de materiais de tôda espécie; ora a execução de obras públicas; ora a realização de serviços de transporte, de luz, de fôrça motriz, etc. Acresicentem-se ainda os contratos de locação de serviços, e outros tantos relativos a uma infinidade de elementos técnicos, que văo passando ao Govêñ a responsabilidade de certos serviços e mesmo de certas industrias.

Dêsse modo, podemos hoje sorrir da candura de ARTHur $\mathbf{S}$. THOMAS, que ainda em 1919 escrevia 15: "comparado com a problema de compras de algumas de nossas grandes emprêsas, as compras do govêrno são umo problema ínfimo. Os negócios do govêrno são, em sua maior parta, rotineison, tornedos fàcilmente exequiveis por uma organização adequada e pala prática de planejar o problema total das compras com grande antecedência das necessidades imediatas".

13 DoEept Voy MaYR, Historia dei Derecho Romeno, Barcelons, 1926, livrc I, sec. Ii. cap. Iri.

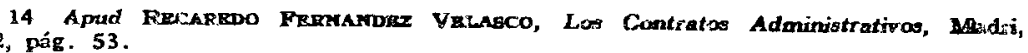
1922, pág. 53. päg. 3.

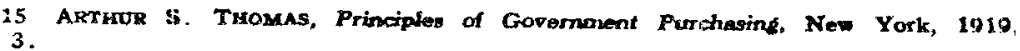


E termina: "o curso dos negócios do govêrno é, via de regra, plácida, em confronto com as necessidades urgentes de uma estrada de ferro ou uma grande emprêsa industrial"...

Hoje, a realidade é muito outra; e o problema ainda mais se complica quando sabemos que, em razão mesmo de sua crescente complexidade, as ptáticas contratuais entre a Administração e o particular vão buscando um simplismo factício, firmando-se espontâneamente em algumas regras práticas que autores como Jizas tentariam esquematizar.

A pletora administrativa vai exigindo racionalização até do modo de contratar. Assim, vai se tornando cada vez mais dificil identificar os contratos administrativos, pois que, na realidade, êles se perderam num processo natural de simplificaçâo, em que se vão reduzindo os trâmites das convençōes solenizadas ou do perfeito gré à gré, se impossível.

Fruto dêsse processo natural de simplificação formal, a tendência hodierna se descobre, como afirmam CarLomagno, WAINER e outros, para firmar-se o aspecto interno do contrato "no caráter coletivo de adesão e norma" e o aspecto externo, "no caráter de contrato formulário, esquematizado, e geralmente expresso" 16.

Dêase modo, ou contratando como pessoa privada, ou contratando como pessoa universal; ou contratando por simples representação, como querem uns, ou contratando por meio de uma relação sai generis, como querem outros - certo é que o Estado moderno, levado de roldāo pelos jogos capitalistas, tem que trabalhar e contratar como qualquer emprêsa privada, tangido como qualquer de nós pela inevitável lei econômica da oferta e da procura.

Não há estranhar, pois, a complexidade atual das questōes que confinam com os contratos administrativos, as quais pecam também pela indecisão com que se procura esquematizá-las. Problema que vai culminar com os conceitos pusilânimes da capacidade civil do Estado, e dos seus discutidos direitos subjetivos, de um lado; com a diferenciação, muitas vêzes impossível, entre direitos e interêsses, de outro; com a responsabilidade civil do Estado ou seus processos de representação jurídica, de um ângulo; com a paridade de vontades ou a não comencialidade das coisas públicas, de outro; o conceito de contrato administrativo é na realidade um mundo em caos.

Em favor de mais fácil compreensão entre todos êstes intricados problemas, vai sendo hoje vencedora a tese de PAUL LABAND, que separou os contrator administrativos em contratos de Direito Público - aquêles em que um contratante fica aubordinado a outro, como nos casos do emprêgo público, naturalização, etc., e contratos de Direito Privado - que se referem a "interêsses pecuniśrios" 17 .

Trabalhando a teso de LABAND, os italianos esquemstizam hoje a matéria em duas partes, como se pode ouvir de Adol.fo Giaqunnto, no Nuovo Digesto Italiano: "uma coisa é contrato administrativo, outra coisa é contrato de Direito Público".

E continua: “objeto do contrato de Direito Público é uma coisa que não tem valor de troca, é pròpriamente o exercício de uma função pública, de um serviço ou de uma atividade exercida pelo Estado, em regime privado; no contrato administrativo o objeto, ao contrário, é constituido de coisas ou obras que tenham valor de troca ou plenos caracteres de comercialidade".

16 JACOEO WAINrR, Contratos Administrativos (ouminiotros, abras y oervicios), Buenos Aires, 1939, pág. 11.

17 Paul Lamaxd, Le Droit Public de l'Empire Allemand, Paris, 1900, tomo II, páz. 100. 
Temos, pois, de uma parie, o Estado agindo como pessoa universsi, exn nome do jus imperii, mantondo condição de superioridade sôhre o cura contratante, mas, entende-se, nāo vsondo desta superioridade como simplí fôtça coatora, o que o levaria a siamples atos de comando.

De outra parte, temos, nẽo o Estado diretamente, mas a Administraçã Pública agindo como simples pessoa privada, submetida ao direito comu - tanto substantivo, cono formal.

Sāo exemplos típicos do segundo caso os por nós já citados, e mesmo concessão do serviços de utilidade pública; são exemplos do prixneiro caso \& autorizaçōes para gôzo de serviços fúblicos, as doaçốes de títulon honorífico o reconhecimento de uma pessoa juxídica, etc. - atos todos exr que a vor tade individual opera apenas como "elemento para a ralidade do ato admini trativo", como ensina Glaquinto ${ }^{18 .}$

Corao se percebe, tais ocorrências só não se restringem apenas ao ân bito dos simples atos administrativos, justamente porque, para 3 ua validad a aceitação por parte do interessado é de "importância essencial para a fo rnaçāo do vínculo obrigatório" 19.

III -. Como vemos, entre o mero ato administrativo, que sempre te: eficácia juridica - quer o relativo às funçōes próprias da autoridade adm gaistrativa, quer os relativos à gestäo patrimonial - o contrato de Direi Fúblico - em que, afinal, a vontade individual é tambérn elemento prep żente - estäo os contratos administrativos pròpriamente ditos.

O ato adrninistrativo prescinde de acôrdo de vontades; a contratı c Direîto Público depende de um consenso que se pode efetuar a posteriori.

Existirão realmente contratos administrativos, em que, como num co: trato privado, o acôrdo de vontades deve efetuar-se integralmente, e a priori

Na verdade, classificar tais contratos dentro do Direito Público ou \& Direito Privado pode parecer obra de somenos. Cono disse Cammeo, "lor que se diz que o vinculo é, em tris casas, constituído de obrigaçōes recípros ez lege, diz-se quanto basta. E' sobremodo indiferente definir se, para , fins de nosso tema, o vínculo é píblico ou privado. Pode ter um o cut caráter, porque pode criar abrigaçōes ex lege jure privato, on jure public mas é inútil aprofundar êste ponto" 20 .

A tentação, pntém, de explicar convenintemente um pródrotno juridi é um pecado de que se não pode livrar o jurista. Dai, o problexna vir-se ete rizando nas sogitaçōes dos especialistas na matéria. E porque realmente assunto é dos naais transcendertes, é que por certo as soluçöes propostas nim se perdem num antagonismo irremediável.

Sem dúvicia, o cumo da questäo está naquele ponto que Jìzze indico a falta de paridade entre a vontade estatal a indiridual, já que cada on funciona em órbita diferente, e ainda mais: jâ que a órbita da vontade a Estado é prevalecente. Por êsse motivo, näo podendo haver consenso licit

18 Nuovo Dikesto Italiano, oo. cit., Contrati di Diritto Pubblico.

19 idem, ihidert.

20 Crsarr Camaro, I Contrati delle Pubblica Amministrazione, Firenze, 193 påg. 50. 
não haverá nunca um contrato, pois que, pela sua própria história, êste, desde Uupuno, se identifica com as conventionis jurris gentium, como autentiea o fragmento 7 do Digesto.

Assim, viciado o consenso - a corventio, estaria viciado o contrato.

IV - Para explicar a passibilidade do consenso entre o Estado e o indivíduo têm surgido muitas e muitas teorias, que não chegam nunca a ser de-

Temos para nós que aquêle clássico silogismo estaria perfeito, se nāo finitivas.

se tratasse justamente de contratos administrativos. Para fundamentar, porém, - nosso ponto de vista, é mister aventar alguns pontos da evolução do conceito de contrato, dos quais, porque muito nos facilitarão a tarefa, começaremos a tratar.

Como disse Riccoвono, "não se encontra nas fontes latinas uma definição de contrato" 21. Ao contrário, ela é fàcilmente indiciada nas fontes gregas, como "pactio duorum pluriumve in idem placitum et consensus", na definição de Trórllo:2, que o identifica com o simples consenso, a convenção.

A carga juridica que os romanos nos legaram foi, porém, uma transfiguração do instituto grego: é que, pejados daquele irredutivel formalismo o qual, como nos deixam antever romanistas como VoN IHERnN, era a grande fôrça dramática de seu direito - os romanos só compreendiam o contrato principal fonte de obrigaçōes - estreitado num formalismo irrevogável. Assim, enquanto no direito grego, figuras como a emptio-venditio, a locatioconductio, a societas, o mandatum, etc., existiam muitas vêzes com os característicos de simples pactos, no direito romano exigiam rígidas fórmulas de consenso, a não ser que o praetor os declarasse isentos de fraude e valendo como excegãa. "Nuda pactio obligationem non parit, sed parit exceptionem" 23.

Vê-se, pois, que, conforme a gradação espontânea das formas de constituir obrigaçöes - "re, verbis, litteris", como lembra GAlo - tendiam os pactos para o formalismo escrito. Assim, o próprio muturum, ou o pignus (eminentemente reais); ou o doctis dictio ou a astipulatio (eminentemente verbais) foram passando a simples arremedos dos contratos literais, como os singrapha ou os chirographa.

Só até à época adriânea é que a conventio, pressuposto geral dos negócios bilaterais, era um gênero de que os contratos eram a espécie. Como dizia o jurista Prdio, que viveu no fim do século I e princípios do século II, e que foi o primeiro a dar valor prevalente ao consenso como elemento essencial aos contratos, "conventionis verbum generale est, ad omnia pertinens, de quibus negotii contrahendi, transigendique causa consentiunt, qui inter se agunt" 24.

Irremediável, porém, os contratos solenes se iriam mais e mais generalizar. 'E' que talvez a fides - que CícERo ${ }^{25}$ definiu tão bem como ele-

21 Salvatore Riccobono, in Nuovo Digesto Italiano, op. cit.

22 TEófILo, fr. 1, $\S 2$, D., de pactis, 2, 14.

23 Digesto, fr. 7, § 4 .

24 Apud Ulpiano, in fr. $1 .^{\circ}, \S 3 .^{\circ}, \mathrm{D}$. , de pactis, $2,14$.

25 "Fides, dictorum conventorumque constantia et veritas, ex quo credamus, quia fiat quod dictum est, sppellatam fidem". In De officis, I, 23. 
mento imprescíndivel à convenção -... estivesse entrando em decadência... Deska maneira, a corrente dos negócios bilaterais acabou por culminar no valor das fórmulas a não dos seus elementos essenciais. Se a fides era impïescindível à conventio, a fórmula era imprescindível à sua validado. Provar ao praetor que se haviam ou não corttraído taîs ou quais obrigaçōes passou a * questão de rnera interpretação gramatical, como o testemunhs o vêzo de acrescentar-se aos contratos, no afã da bem estipular o que se pretendia, yerdadeiros apêndíces essenciais - que podiam modificar-lhes os naturais efeitor - os pacta adjecta, verdadeiros pactos marginais.

Era, pois, bern clara a função meramente instrumental dos contratos, que. como escritura dos pactos, constituíam simples elemento formal de revalidaçãc cio primitivo nuda pactio. Só depois surgiria a palavra contrato para substs. tuir o primevo nivum ou nexun? (do verbo nactere - higar), antes näo caracterizedo pelo instrumento escrito.

Como se vê, por essa inversão sistemática de vaiores jurídicos, o nexurr. -_ vínculo essencial - foi sendo escluecido e substituído pelo contracto vinculo formal.

Parecenos, portanto, de interêsse bastante redurido a discussão de autores como FrrRari, Prrozzi e Bonfante, que se empenham por descobrir se : palavra contrato significa o negócio, o vínculo juridico cu a voluntariedadł do ato...

E' bern verdade que, por ume espécie de atavismo juridico, sós sempit estamos predispostos a aceitar on contratos coma figuras essenciais. Itst fexômeno de deturpsção conceitual porém tem razóes plausiveis: invadido e império romano, dá-se o inevitável choque entre o direito romano - eminente mente formalista - o o direito tedesco - eminentemente simbolista. O ger mano primário, para quem o simples apêrto de mão era matéria contratual nāo conseguiria jamais tratar, mesmo na qualidade de conquistador, corn . latino, de tradiçāo formal inextirpável. A solução estava na adesão aos pre coiros romanos. E os getmencs aprendem a escrever contratos para as trans ferências imobiliárias; $\theta$ surgen também os testamentos à meneira romana corso o thingatio, muito parecido ccm o calatiz-comiris, exigindo-se tambén aqui o testemunho do povo. Generalizando a tendência, reconhecem os inva sotes a necessidacie de sistematizar melhor o próprio direito das obrigaçóa e a matéria dos contratos. E dai os contratos reais - wadia ou festuca: o: contratos verbais - Eiutamento; e cs contratos escritiss - charta.

O simbolismo tedesco, contudo, näo cederia tão fàcilmente... E eis qu nos surgem os germânicos cercando os contratos formais de solenidades ines peradas. Surgem, por exemplo, as solenidades da investitura, sem as quai zenuum contrato era válido. E, paradoxalmente, a tradictio da charta passol a ser um ato tão solene como a antiga tradictio da coisa...

E' que, em suma, o instrumento contratual, para o simbolismo germânicc passara a representar a proprio objeto do contrato. O contrato, pois, se trans forma em instituto substantivo, e, perdendo seu primitivo caráter formai passa a ser o gênero de que a conventio seria a espécie...

I foi egta a noçāo que nos chegou, através dos séculos. 
V - Enquanto se trata de contratos privados, a distinção entre o elemento formal e o essencial näo representa grande conquista. No terreno público, no entanto, as vantagens são de grande monta para a simplificação do problema. E' que o formalismo de um pacto administrativo, teòricamente, é um fator de somenos, já que o contrato, sendo oficial, está acima de qualquer impugnação, valendo como ato solene. (Esta circunstância é tanto mais importante quando so sabe que, como VRLASCO, a maior parte dos autores insiste no critério formal para distinguir os contratos) ${ }^{26}$. Dêsse modo, afastado sumàriamente o aspecto tormal da questão, caímos no terreno puro da convenção, do consenso, do nivum. E então podemos discutir, sem complicaçóes adjetivas, as teses fundamentais do assunto:

I - pode o Estado acordar com o particular?

II - havendo acôrdo, será êste de Direito Público ou de Direito Privado?

Em primeiro lugar, devemos responder a outra pergunta: tem o Estado, como sujeito de direitos, como sujeito capaz de agir, os dois elementos que caracterizam o aspecto dinâmico da personalidade, isto é, vontado e manifes. tação dessa vontade?

E' claro que sim. Negar tais prerrogativas à Administração Pública, que sempre contrata em nome do jus gestionis do Estado, oquiparando-se, pois, à pessoa privada, era negar a capacidade de contratar de qualquer pessoa jurídica.

Dêsse modo, parece-nos bizantinismo continuar indagando uma evidência. A. Administração Pública pode acordar com o particular. E' certo que se pode objetar a clássica prevalência da vontade do Estado, o que levou alguns autores - como Rouvì̀RE - a concordar serem sempre os contratos administrativos contratos de adesão, já que, no caso, não havia aquêle processo de accordage que caracteriza o marché-de-gré-à-gré. Somos, porém, de parecer que nos contratos administrativos há sempre um acôrdo de vontades que pode raia: mesmo pelo accordage. Quando nāo explícitos, como em muitos casos, ao menos implicito. Na realidade, se o Estado denuncia tal ou qual vontade de contratar, através de uma policitatio, duas hipóteses podem surgir: 1. ${ }^{2}$ ) tal vontade é aceita pelo particular; $2 .^{\text {a) }}$ nenhum particular aceita a oferta . Que faz o Estado, verificada a segunda hipótese? Expõe outra oferta, que procura compensar as causas da não aceitação da primeira, de acôrdo com uma sondagem em tal ou qual mercado, inclusive o do trabalho. E fará outras ofertas, sucessivamente, até que consiga um outro contratante. Como se vê, aquêle ato de regatear - tão importante para alguns autores - ai aparece perfeito.

Poder-se-á objetar que um Estado despótico, ao invés de modificar a proposta, recorreria à requisição forçada. Sim, de acôrdo; mas isto nos parace outra história.

Quanto ao Estado contratar mediante representação através da Administração Pública, também nada há a objetar. E' sabido que contratos tendom cada vez mais a uma uniformidade e impessoalidade absolutas: qualquer emprêsa, hoje, contrata por meio de seus prepostos e segundo fúrmulas contratuais preestabelecidas, com característicos às vêzes intangiveis. Hcje, dinicilmente o empregado de uma grande emprêsa conhece o seu patrão. E seus contratos de trabalho são quase sempre de adesão, como os dos servidcres públicos. 
VI - Resta-nos responder à última pergunta : a conventio entre o Estado - o particular será um instituto de Direito Público ou de Direito Privado?

Alguns autores, como POSADA :i, estudam a matéria exclusivamente dentro do âmbito do Direito Público. "Um contrato administrativo é um ato cie gestāo de interêsses, verificado pela representação específica da administraçāo do Estacio segundo as exigências racionais da relação contratual e para fins administrativos", escreve o grande tratadista de Oviedo. E te:mina acrescentando que a teoria geral dos contratos administrativos abrange tôda a atividade administrativa do Estado relacionada com tôdas "as formas contratuais para fins de ordem juridica-social".

Outros, como TAvares de LIRA Fano, 28 concluem que "os contratos administrativos nāo se confundem com os de direito público a os de direito privado", constituindo categoria à parte.

Outros, ainda, como CESARE CAMMEo, levam os contratos administrativos para o plano exclusivo do Direito Privado. Como escreveu aquêle tratadista italiano, "o direito público regula todos os atos da Administração Pública durante o processo de sua formaçáa. $O$ direito privado intervém para diacipliná-los, já depois que êstes estão formados". 29 .

E termina: "os contratos da Administração Pública estão sujeitos a direito privado; lembre-se que, para êstes, vale, segundo cada caso, o Direito Civil ou o Direito Comercial" 36.

E Cammeo lembra mesmo que a esfera do Direito Comercial tenderá cada vez mais a expandir-se nos regimes de economia controlada empolgando também o Diraito Público.

Se tentássemos encompridar a hista, veriamos que cada tratadista se permite ter idéies que quase sempre não coincidem com as alheias, embora se possa perceber que a tendência mais geral é trazer os contratos de Administração Pública para a órbita do Direito Público. Farece-nos, prorém, que sāo baldados todos êstes esforços em discernir, por meio de pressirpostos, cue a spectos contrazuais pertencern ao Direito Privado ou ao Direito Público.

Como escreveu ADolfo GlaquLNTo: "não se pode dizer, de modo geta", que todos êstes acordos (os contratos administrativos) assumem sempre o ceráter e o conteúdo dos contratos de direito público, ou de diréto privado; a qualificação é, ao contrário, o resultado de uma indagação analítica concreta, que por certo não pode ser feita neste ponto" 31.

Além do mais, parece-nos mesmo năo ser hoje de real monta uma diferenciação completa entre o Direito Püblico e o Direito privado, par isso qúe qualquer tentativa nesse sentido terminará sempre num círculo vicioso. MayRICR HAURIOU, pOr exemplo, estudando o problema dos limites entre o direito Administrativo e o Direito Comum, conclui pela interpenetração dos dois direitos, rnedierte um sistema de regras e exceçöes. Como afirma, o Direito Administrativo só é independente do Direito Comum na medida que as prerro-

27 Aoolfo PosnoA, Trotado de Derecho Administrativo, Madri, 189\%, tomo Ir, pán. 263.

28 Tavares ne trea Funo, Contrates Administrativos, Fio, 1941, pég. 187.

29 Cesarze cammeo, op. cit., pág. 32.

30 Cesare cammo, op. cit., páa. 72.

31 Apol,zo Glaquerto, in Nuovo Disesto italiano, op. cit. 
gativas legais o possibilitem, acontecendo, ì vêzes, que um incidente qualquer o prende à órbita do Direito Comum, "que o contém e que o espreita (guette)" 32.

Tais idéias, porém, representam uma perfeita antitese da clássica corrente tedesca de Gerber, JELlinkr e outros, segundo a qual o Direito Privado á que se acha condicionado ao Direito Público. "Sem direito público não possível o direito privado", é o brocardo que ressalta da teoria do direito reflexivo - reflexrecht - que em 1852 GRRBER lançava, e que culmina no seguinte pensamento: "o ponto de partida para bem compreender-se o vínculo existente entre o cidadão e Estado, é o direito soberano, independente e onipotente dêste: os direitos dos cidadãos nada mais são que efeitos refíeros do direito pertinente ao Estado e, como tais, só existem enquanto existir o Estado e sua soberania" 33 .

Dêsee modo, se Hauriou nega ao Estado a autonomia de direitos privados objetivos, Gerarer, por sua vez, nega ao cidadão direitos públicos subjetivoa. Conciliá-los, pois, não deve ser tarefa humana.

Para evitar bizantinismos dêste quilate é que nos parece irrecusável a necessidade de aplainar certos pontos. De um ângulo teórico bastante elevado, podemos acreditar na reciprocidade absoluta entre o Direito Público e - Privado; se os direitos subjetivos do particular são reflexivos - já que emanam do poder estatal - os direitos do Estado também são reflexivos, visto que emanam do povo que o constitui. Assim, há entre os dois direitos verdadeira reciprocidado de condicionamento, que seria inútil querer negar ou diferenciar. Seria, como tem sido até hoje, tentar remover montanhas, cnde existe apenas a planície.

Reafirmamos, pois, nossas convicçōes acêrca da impossibilidade de uma classificação in-fonte para os contratos administrativos, dentro do Direito Público ou Privado.

De modo geral - agindo o Estado como pessoa privada, ou como autoridado - as raxóes filosóficas que dāo fôrça obrigatória aos contratos firmados pelo Govêrno ou pela Administração Pública serão sempre, como as razōes do Direito Privado, discutidas durante séculos dentro das mesmas teses conhecidas para o direito individual, quer a racionalista, do pacto social de Roussenu, ou a utilitarista, de BENTHAM; ou a da ocupação, de KANT e HEGE; ou a fórmula mista de dever e cooperação de KRAUSE; ou mesmo a tese moral, de AHTRess.

Isto porque, como para os atos administrativos explicou MEUcci ${ }^{34}$, - grande professor da Universidade de Roma: "nem a responsabilidade nem a liberdade, nem o objetivo nem a autoridade do poder permanecem diminuídos. A liberdade do poder, que se diz autoridade, não é coisa essencialmente diversa da liberdade do cidadão, que se diz simplesmente liberdade: c conceito juridico é o mesmo".

32 Maurac: Hauruov, Précis de Droit Adminiatratif et de Droit Public, Paris, 1914, pág. 86.

33 Apud V. E. OrLasdo, Primo Trattato Completo di Diritto Amminiatrativo Italiano, Milano, 1897, vol. I, pág. 114.

34 Lofenzo Mrocc, Istiturioni di Diritto Amminiatrativo, Torino, 1898, pát. 71. 
YII - Do exposto, deduz-se a completa falência das classificações d base causal para os contratos administrativos. E isto porque sempre anc defrontaremos com um impasse: ou reconhecemos a prevalência da órbita $\mathrm{C}$ yontade estatâl contra a órbita da vontade individual - e então räo teremc urna conventio perfeita, ou nẽo reconhecemos aquela prevalência, e entã eliminaremos a necessidade de diferenciar entre aquelas duas órbitas. No pr meiro caso, não haveria mais interêsse em conceituar os contratcos administre tivos, jú que êles estariam viciados criginàriamente; no segundo caso, teríamc o contrato perfeito, mas não havia por onde classificá-lo, por isso que, aind quando nos restassem duas órbitas juridicas, elas seriam de efeitos equivalente:

Dêsse modo, opinamos por um optimum mais prático para a k̇nclusão do contratos administrativos num dos setores do esquema clássica do Direito

Já que se nos afigura impossíyel uma classificação baseada em suas fcnte primárias, enveredemos pelos efeitos dos contratos administrativos, tentande Ihes uma classificação em bases teleológicas, quer dizer, tendo em vista sub causas tinais. E nos parece muito simplificada a questão: entre o interêss individual em foco e o interêsse coletivo em jôgo, não há como titubear. $\mathbf{S}$ os contratos privados podem ser considerados de ordem pública, não se dever negar tal prerrogativa aos contratos administrativos, em que, alén do raai: êste característico se extrema. Será irrisório, pois, que o Estado se abstenh de salyaguardar o interêsse coletivo por meio de sua natural via de proteçã - o Direito Público, sempre çue tal imperativo se apresente.

Nesta época em que beiramos tão rudemente o materialismo histórict seria pueril vo?tar ao pieguismo dos Labovlaye passadistas, cerceando a Estado um dos seus instrumentos de afirmação - a prevalência do Direito $P \dot{r}$ blico, que deve estar sempre atento à execução dos contratos administrativo: Com esta inniciativa, deslocamos o interêsse da questão do seu ponto inicial a formação do contrato, para o ponto final - sua execução. E neste camp não cabem controvérsias. Passada a trágica experiência mundial, exn qu vimos os governos açaimados pola genância inescrupulosa de algumas holding compenias "3ี, não se compreenderia insistíssemos na inconseqüência palma de prosseguir determinando a longo prazo o aspecto social dêste ou daquol serviço de utilidade pública, desta ou daquela medida governament:

Em outras palavras: dadas as transformaçōes vertiginosas e muitas vêze insuspeitáveis do potencial econômico, é de todo imprescindível que a exe cução das contratos administrativos fique sujeita àquela teoria da imprevisa que JżzE expōe no terceiro volume de sua obra clássica, segundo a qual, añnd: que ocorrarn graves modificações econômicas, a máquina do govêrno não poder: parar, nem qualquer serviço de ustilidade pública deixará de ser prestado Assìm, cingido o contrato pelo Direito Público, o Eistado obrigará o outr contratante à sua execução, embora com prejuizos que poderão depois se indenizados, merliante ação de regressão.

F aqui fica a conseqüuêncỉa mzis transcendente da afirmação de nossı pensamento: nos contratos administrativos, a cláusula rebus sic stantibus s pode ser invocada pelo Estado.

35 Not Estados Unidos, a crise foi täo aguda que levou homens cono Foosivel \$ pensaren nume nova Declareçäo dt Inckependência 